\title{
Evaluation and Development of Non-Exercise Prediction Models of Maximal Oxygen Consumption in Azerbaijan-Iranian Young Men 檢测阿塞看疆伊朗男子的最大攝氧量推算公式
}

\author{
M. Khorshidi HOSSINI \\ Department of Physical Education and Sport Science, \\ University of Islamic Azad, Ardabil branch, IRAN
}

\author{
A. VALIZADEH L. BOLBOLI A. MEAMARBASHI \\ Department of Physical Education and Sport Science, \\ University of Mohaghegh Ardabili, IRAN
}

\section{何斯尼 \\ 伊朗伊斯蘭阿扎德大學體育及運動科學系 \\ 維利莎特 保布利 梅瑪巴斯 \\ 伊朗阿爾德比利大學體育及運動科學系}

\begin{abstract}
The purpose of this study was to develop a regression equation to predict maximal oxygen consumption $\left(\mathrm{VO} 2_{\max }\right)$ based on non-exercise (N-EX) data and to investigate the validity of these equations in healthy young men. One hundred healthy men (age: 18-26 years) were randomly separated in two equal groups $(\mathrm{n}=50)$. All participants, successfully completed a maximal graded exercise test $(\mathrm{GXT})$ to assess $\mathrm{VO}_{\max }$ (Mean $=45.56 \mathrm{ml} \times \mathrm{kg}^{-1} \times \mathrm{min}^{-1}, \mathrm{SD}=4.14$ ). The N-EX data collected just before the maximal GXT including participants' age; body mass index (BMI); perceived functional ability (PFA) to walk, jog, or run given distances; and current physical activity (PA-R) level. Methodological differences among these methods (new equation and GXT in the validation group) were analyzed with Bland-Altman (1986) method. A good correlation coefficients were observed between $\mathrm{VO}_{2} \max$ and body mass index (BMI) $(\mathrm{r}=-0.50)$, PFA $(\mathrm{r}=0.71)$ and PA-R $(\mathrm{r}=0.70)$ in the development group $(\mathrm{p}<0.05)$. Multiple linear regression generated the following N-EX prediction equation: $\mathrm{VO}_{2} \max \left(\mathrm{ml} \times \mathrm{kg}^{-1} \times \min ^{-1}\right)$ $=47.718-(0.38516 \times \mathrm{BMI})+(0.8541 \times \mathrm{PA}-\mathrm{R})+(0.2539 \times \mathrm{PFA})$. When new $\mathrm{VO}_{2} \max$ prediction equation were applied to the validation group, high agreement were also observed between measured $\mathrm{VO}_{\max }$ by GXT and predicted $\mathrm{VO}_{2} \mathrm{max}$ (mean $\pm \mathrm{SD}$ : $0.58 \pm 2.53$ ) ( $\mathrm{p}<$ 0.05). This study provided an N-EX regression model that yields relatively accurate results and it is a convenient way to predict $\mathrm{VO}_{\text {max }}$ in Azerbaijan-Iranian young men with a similar cardiorespiratory fitness level. Authors recommend further studies to elucidate generality of the new equation.
\end{abstract}

Key words: New Equation, $\mathrm{VO}_{2} \max$, Perceived Functional Ability, Physical Activity

\section{摘 要}

本研究旨在計算預測年青人最大攝氧量的公式, 邀請了100位健康男士, 分成兩組進行測驗。結果顯示, 推算最大攝氧量的公式如 下: $\operatorname{VO} 2 \max (\mathrm{ml} \times \mathrm{kg}-1 \times \mathrm{min}-\mathrm{l})=47.718-(0.38516 \times \mathrm{BMI})+(0.8541 \times \mathrm{PA}-\mathrm{R})+(0.2539 \times \mathrm{PFA}) 。$ 


\section{Introduction}

Cardiorespiratory fitness ( $\mathrm{CRF}$ ) is the ability to perform dynamic, moderate-to-high intensity exercise with the large muscle groups for long periods of time (ACSM, 2000). Cardiorespiratory fitness depends on the respiratory, cardiovascular, and skeletal muscle systems and, therefore, is an important component of health and physical fitness. The assessment of CRF is valuable when teaching individuals about their overall fitness status, developing exercise programs, and stratifying cardiovascular risk (Bradshaw et al, 2005). The ability to perform aerobic exercise is associated with the level of aerobic power or maximal oxygen consumption $\left(\mathrm{VO}_{\max }\right)$ which is generally recognized and frequently used as the best single index of individuals cardiorespiratory fitness (Armstrong, Welsman, \& Kirby, 1988; (Larsen et al, 2002). The most precise assessments of $\mathrm{VO}_{\text {max }}$ performed directly in a laboratory setting using specialized equipments where highly motivated subjects perform a maximal graded test (GXT) until exhaustion while using calorimetric analysis of expired gases (Dolgener et al, 1994; Grant, Joseph, \& Campagna, 1999; Greenhalgh, George, \& Hager, 2001; Larsen, 2002). VO2 $2_{\max }$ is the most accurate parameter to assess CRF, however, the test requires expensive equipments, considerable space to setup the equipments, and high skill personnel to run the test. In addition, maximal GXT is not applicable on some individuals because the test requires strenuous exercise to the point of volitional exhaustion. Because of this, some older or higher-risk individuals should not perform the test without medical supervision (Bradshaw et al, 2005). Therefore, fitness testing or testing larger population is not always practical by means of measuring maximal oxygen consumption (Dolgener et al, 1994; Grant, Joseph, \& Campagna, 1999; Greenhalgh, George, \& Hager, 2001; Larsen, 2002). Due to the possible drawbacks of maximal GXTs and direct measurement of $\mathrm{VO}_{2} \max$, submaximal exercise tests are available and provide an acceptable prediction of $\mathrm{CRF}$ and $\mathrm{VO}_{2} \max$. Submaximal exercise tests using prediction variables such as age, gender, body mass, exercise pace, and exercise heart rate to estimate $\mathrm{VO}_{2} \max$ (ACSM, 2002). Although submaximal exercise is not accurate as maximal GXTs, but it is easier to perform, require less time and efforts to complete, and can be administered at lower costs and lower risk (Bradshaw et al, 2005). These tests use a variety of exercise modes including cycle ergometry, stepping and walking, jogging or running on a treadmill or track (ACSM, 2000; Donnelly et al, 1992; George et al, 1993; Oja et al, 1991). Other methods that do not require exercise are also available to predict $\mathrm{VO}_{\max }$ (ACSM, 2000). Non-exercise (N-EX) regression equations provided a convenient estimate of CRF without dependency to perform a maximal or submaximal exercise test (Davis et al, 2002; Larsen et al, 2002). This approach is inexpensive, time-efficient, and realistic for large groups. To date, N-EX predictor variables are include age, gender, BMI, percent body fat, physical activity rating (PA-R) (Heil et al, 1995; Jackson et al, 1990) and perceived functional ability (PFA) (Bradshaw et al, 2005; George et al, 1997). The PFA includes simple questions which ask from subjects to rate their ability to exercise at a comfortable pace for one and three miles. Studies show N-EX equations are relatively accurate and provide a quick and easy way to predict $\mathrm{VO}_{\max }$ (George et al, 1997, Heil et al, 1995, Jackson et al, 1990). Therefore, CRF prediction models can be used to reasonably characterize the fitness level of a cohort using data that can be obtained from a questionnaire. Accordingly, predicted CRF values may be useful as an exposure variable in large epidemiologic studies in which exercise testing is not feasible (Matthews et al, 1999). The developing of non-exercise (N-EX) prediction equation in independent groups is importance, because $\mathrm{VO} 2_{\max }$ is based on many different physiological characteristics, it has become a common descriptive variable like stature, body mass, age (Howley, Bassett Jr, \& Welch, 1995), gender and potential ethnic-related and CRF may vary between subgroups of the population. In additional, same as all self-reported data, a given response to the PFA and PA-R questions may be influenced by a variety of social, cognitive, and psychological factors (George, Stone, \& Burkett, 1997).

The purpose of this study was to develop a regression equation to predict maximal oxygen consumption $\left(\mathrm{VO} 2_{\max }\right)$ base on non-exercise $(\mathrm{N}-\mathrm{EX})$ data and to investigate the validity of these equations in Azerbaijan -Iranian young men.

\section{Materials and Methods}

Participants: one hundred healthy university students (age: 18-26 years) recruited in the study. Participants were randomly separated into two similar groups: Fifty subjects in the development group and another 50 subjects in the validation group. Prior to participation, volunteers read and signed an information consent sheet and completed a physical activity and health readiness questionnaire 
that was previously approved by the University Ethical Committee (Wasserman et al., 1999).

\section{Procedures}

Measurements performed by exercise physiologists in the Sport Physiology laboratory (43\% humidity, 25 (C). Their height and body weight were measured and recorded while wearing lightweight clothing without shoes, to the nearest $0.1 \mathrm{~cm}$ and $0.1 \mathrm{~kg}$ using SECA electronic height and weight scale. The mean values of two measurements were used for data analysis. All participants were instructed to get sufficient sleep (6-8 h) and avoid food, caffeine, tobacco-products or alcohol $3 \mathrm{~h}$ prior to testing (27). Before completing the test, each participant read a page of written test instructions. Instructions about the maximal GXT procedures including the protocols, heart rate monitoring and rating of perceived exertion (RPE) scale (Borg, 1982) were given to all participants prior to testing. All participants completed a maximal treadmill GXT.

Maximal Treadmill Graded Exercise Test: Participants performed a maximal GXT using a maximal protocol that developed by Georgy et al. (1993). The treadmill exercise protocol was completed on a Quinton 3.0 treadmill (Quinton. Club track, model: 3.0, USA). Following the warm-up, participants rested for $\sim 5$ minutes while the test administrator explained the test procedures for the maximal GXT. Following 3 min of walking, participants jogged at the self selected speed between $4.3 \mathrm{mph}$ and 7.5 mph at the zero grade level for an additional $3 \mathrm{~min}$. The treadmill grade was then increased $2.5 \%$ every minute (constant speed) until participants exhausted. The participants' heart rate (HR) and RPE score was recorded at the end of each stage. The VO2 were computed, averaged, and printed by computer every 15 seconds. At the end of exercise heart rate and treadmill speed measured and recorded for each subject. The recorded heart rate at the end of exercise was considered as peak HR for GXT test and was implemented to measurement VO2max.

Non-exercise Questionnaire: Prior to exercise testing participants completed the PFA (George, D., Stone, \& Burkett, 1997) and a modified PA-R non-exercise questionnaires (Bradshaw et al, 2005; George, D., Stone, \& Burkett, 1997; Jackson et al, 1990). The PFA includes two questions that ascertain how fast participants feel they can cover a 1 and 3 mile distance at a comfortable pace. Sum of both 13-point questions is counted as the PFA score (range 2-26). The original PA-R questionnaire rate their level of activity on a 7-point scale over the past month. However, Kolkhorst and Dolgener (1994) noted that an extended time reference might represent participants' overall average physical activity level more accurately (Kolkhorst, \& Dolgener, 1994). Thus, the PA$\mathrm{R}$ questionnaire was modified with a longer 6-month time reference and expanded 10-point scale.

\section{Statistics}

Multiple linear regression test was used to create a VO2max regression model using BMI, PFA, and PA$\mathrm{R}$ as predictor variables. The validity of the VO2max equation (new equation and GXT in the validation group) was evaluated based on the Bland-Altman (1986) method (Bland, \& Altman, 1986). Bland-Altman analysis is a statistical method where compares a mean difference against average values from two different methods (differences between VO2max for each subject were plotted against each subjects mean VO2max of the same two methods to explore any difference in agreement between measurement methods). The solid line on each plot represents the mean of differences and the variations between methods are then presented as a $\pm 2 \mathrm{SD}$, which represents $95 \%$ limit of agreement (the dashed lines). The data were analyzed using MedCalc software, version 8.2.1.0. The level of statistical significance was set at a probability of $\mathrm{P}<0.05$ for all tests.

\section{Results}

Descriptive statistics for the total sample (development and validation groups) are presented in Table 1. All participants achieved a valid VO2max during the maximum GXT with the average $( \pm \mathrm{SD}) \mathrm{VO}$ max equal to $45.56 \pm 4.14 \mathrm{ml}$. kg-1 .min-1. Corresponding HRmax (196.85 \pm 8.1 beats.min-1) and maximum RPE scores (19.53 \pm 0.65$)$ were all indicative of maximum effort. Participants PFA and PA-R scores ranged from 2 to 26 and 1 to 10 , respectively. Each independent variable was statistically significant $(\mathrm{p}<0.05)$ in predicting VO2max. Correlations were observed between $\mathrm{VO} 2 \mathrm{max}$ and body mass index (BMI) $(\mathrm{r}=-0.50)$, PFA $(\mathrm{r}=0.71)$ and PA-R $(\mathrm{r}=0.70)$ in the development group (Table 2). Figure 1 (a-c) provides scatter plots of independent variables versus observed VO2max values for the N-EX regression model in the development group. Multiple linear regression generated the following N-EX prediction equation: 
$\mathrm{VO}_{\text {max }}\left(\mathrm{ml} \cdot \mathrm{kg}^{-1} \cdot \mathrm{min}^{-1}\right)=47.718-(0.38516 \mathrm{x}$ BMI $)+(0.8541$ x PA-R) + (0.2539 x PFA) (Table 2).

Bland-Altman analysis was calculated as a mean difference against average values with $\pm 2 \mathrm{SD}$ for $\mathrm{VO} 2_{\max }$ between GXT and new N-EX equation prediction in validation group (Figure 1.d). The Results of BlandAltman analysis showed that predicted $\mathrm{VO}_{\text {max }}$ by new $\mathrm{N}$ EX equation has high agreement with GXT method. (narrowest margins between limits of agreement).

Table 1. Descriptive Statistics for Physical Characteristics, Exercise and N-EX Data.

\begin{tabular}{lccc}
\hline Variable & Total & Development group & Validation group \\
& $\mathrm{n}=100$ & $\mathrm{n}=50$ & $\mathrm{n}=50$ \\
\hline Age $(\mathrm{yr})$ & $20.43 \pm 1.61$ & $20.42 \pm 1.51$ & $20.45 \pm 1.72$ \\
Height $(\mathrm{cm})$ & $174.86 \pm 4.91$ & $175.42 \pm 5.26$ & $174.3 \pm 4.53$ \\
Weight $(\mathrm{kg})$ & $68.93 \pm 8.29$ & $69.53 \pm 8.34$ & $68.33 \pm 8.3$ \\
BMI $\left(\mathrm{kg} / \mathrm{m}^{2}\right)$ & $22.55 \pm 2.54$ & $22.63 \pm 2.72$ & $22.48 \pm 2.38$ \\
self-reported BMI & $22.95 \pm 2.75$ & $22.85 \pm 2.97$ & $23.06 \pm 2.6$ \\
Body fat $(\%)$ & $12.19 \pm 3.57$ & $12.36 \pm 3.87$ & $12.02 \pm 3.28$
\end{tabular}

Maximal Treadmill Test

$\mathrm{VO} 2_{\max }\left(\mathrm{ml} \cdot \mathrm{kg}^{-1} \cdot \mathrm{min}^{-1}\right)$

HRmax (beats. $\min ^{-1}$ )

$45.56 \pm 4.14$

$45.79 \pm 4.23$

$45.34 \pm 4.01$

RPEmax (15-point scale)

$196.85 \pm 8.1$

$195.55 \pm 7.86$

$198.15 \pm 8.24$

$19.53 \pm 0.65$

$19.51 \pm 0.69$

$19.55 \pm 0.62$

N-EX Questions

PFA

PA-R

$12.71 \pm 5.7$

$12.85 \pm 5.8$

$12.55 \pm 5.51$

$3.93 \pm 1.9$

$4.1 \pm 2.09$

$3.77 \pm 1.732$

All data $=$ mean \pm SD.

PFA $=$ perceived functional ability (2-26 point scale).

$\mathrm{PA}-\mathrm{R}=$ physical activity rating (10 point scale).

Table 2. New N-EX VO2max regression equation in the development group (n=50).

\begin{tabular}{cccccc}
\hline $\begin{array}{c}\text { Zero Order Correlation } \\
\text { Coefficients }\end{array}$ & $\mathrm{p}$ & $\mathrm{t}$ & $\mathrm{SDE}$ & \multicolumn{2}{c}{ Coefficient } \\
\hline--- & ---- & --- & --- & 47.71877 & Intercept \\
-0.501 & 0.0223 & -2.388 & 0.16129 & -0.38516 & BMI \\
0.713 & 0.009 & 2.765 & 0.09183 & 0.25390 & PFA \\
0.706 & 0.001 & 3.488 & 0.24488 & 0.85410 & PA-R \\
\hline
\end{tabular}

Multiple correlation coefficient $=0.821$

Coefficient of determination $=0.6741$

R-adjusted $=0.6469$ 
Figure 1. Scatter plots, regression lines and correlation coefficients between mass specific GXT VO2 $2_{\max }\left(\mathrm{ml} \mathrm{kg}^{-1} \cdot \mathrm{min}^{-1}\right)$ and value of the independent variable: BMI (a), PA-R (b) and PFA (c) in the development group. The solid lines depicted are the least-squares derived best fitting lines. Dashed curves represent a 95\% confidence interval for the regression line. Bland-Altman (1986) plots comparing GXT VO2max against new equation (d). The x-axis represents the mean of both GXT VO2max and new equation VO2max for each subject; the y-axis represents the difference between GXT VO2max and predicted new equation VO2max for each subject. A solid line represents the mean of differences; dashed lines represent the upper and lower limits of agreement (mean $\pm 2 \mathrm{SD}$ ). All data based on VO2max $\left(\mathrm{ml} \cdot \mathrm{kg}^{-1} \cdot \mathrm{min}^{-1}\right)$ determined from methods.

a)

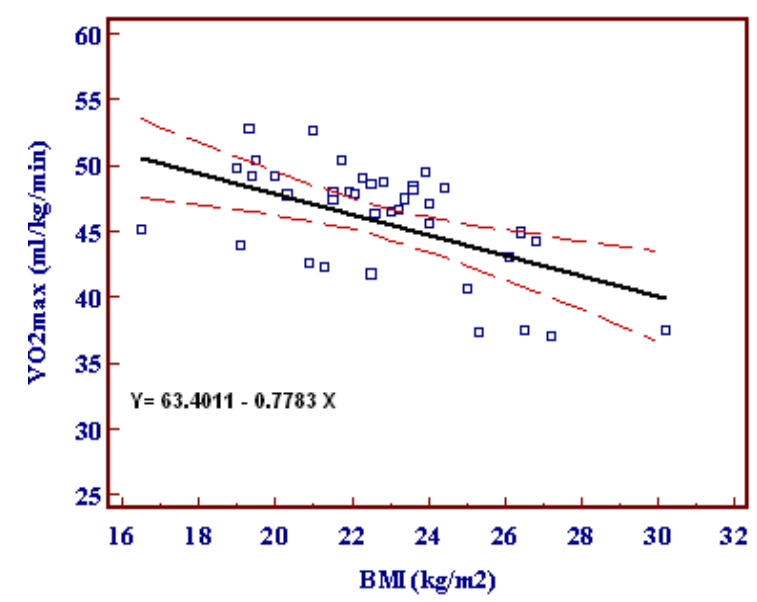

c)

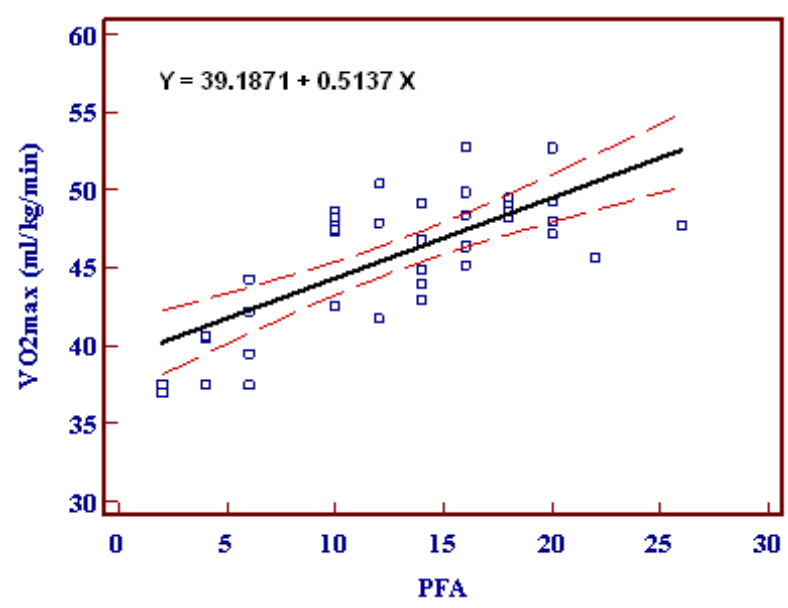

\section{Discussion}

The N-EX regression model developed in this study predicts maximal oxygen consumption (VO2max) accurately $\left(\right.$ Mean \pm SD: $\left.0.58 \pm 2.5 \mathrm{ml} \cdot \mathrm{kg}^{-1} \cdot \mathrm{min}^{-1}\right)$ in this study. The Bland-Altman plots (Figurel.d) describe the agreement (how close one measure compares to another) in $\mathrm{VO}_{\max }$ between GXT method and new N-EX equation prediction in validation group and it is suggested be more useful indication compared to $\mathrm{r}, \mathrm{r}^{2}$, and SEE as to whether one method can be a valid substitution for another (Bland, \& Altman, 1986). The correlations between PA-R, body b)

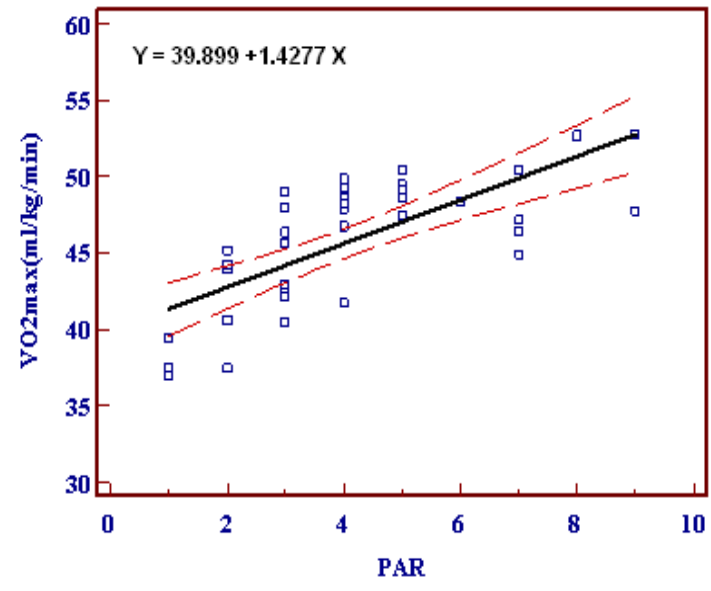

d)

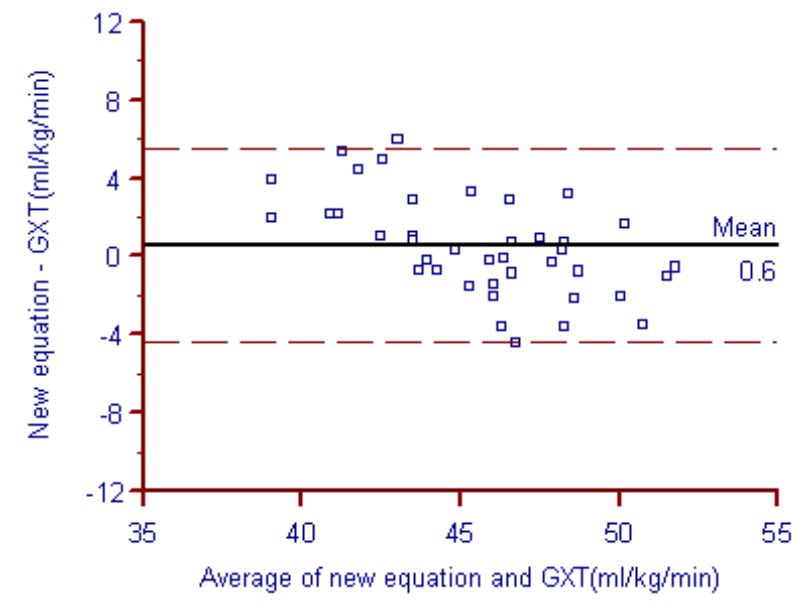

mass index (BMI), PFA and observed $\mathrm{VO} 2_{\text {max }}\left(\mathrm{ml} \mathrm{kg}^{-1} \cdot \mathrm{min}^{-1}\right)$ in the development group equaled $0.70,-0.50$ and 0.71 respectively (Table 2). Thus, for these college students the PFA (a self report of one's perceived ability to perform aerobic-type exercise), BMI and PA-R data were as valuable in explaining observed $\mathrm{VO}_{\text {max }}$ variance as were actual aerobic-type exercise data (Figure 1. a, b and c). A number of studies have documented the relationship between self-report physical activity and $\mathrm{VO}_{\text {max }}(1,14,17,19,25)$. The original PA-R (7-point scale) developed by Jackson et al. (1990) demonstrated a zero-order correlation with observed $\mathrm{VO}_{\text {max }}$ (expressed in $\mathrm{ml} \cdot \mathrm{kg}^{-1} \cdot \mathrm{min}^{-1}$ ) equal to 0.59 
when applied to a heterogeneous sample of males and females (aged 18 to $70 \mathrm{yr}$ ). However, weaknesses specific to the original PA-R question (7-point scale) have been previously discussed. About this issue, Kolkhorst and Dolgener (1994) noted that an extended time reference might represent participants' overall average physical activity level more accurately (Kolkhorst, \& Dolgener, 1994). In another study George et al (1997) compared modified physical activity (PA-R) question of Jackson et al.(20) with the Ainsworth et al. (1992) question and reported the modified physical activity (PA-R) question of Jackson et al.(20) $(\mathrm{t}=3.72, \mathrm{P}<0.0001)$ was a better predictor of $\mathrm{VO}_{\text {max }}$ than the Ainsworth et al. (1992) $(\mathrm{t}=0.54$, $\mathrm{P}=0.59$ ) question (13) and therefore it was used in the regression analyses. The PA-R score is subjective as well and depends on participants being able to distinguish between light, moderate, and vigorous activity. To be accurate, participants must correctly recall their level of physical activity over the past 6 months. Therefore, these small differences may be a result of sample differences (George et al, 1997) or differences in response to the original versus modified PA-R question.

Although the N-EX model developed in this study presents excellent results and in the previously cited studies, the PFA data improved the ability of the N-EX regression models to accurately estimate $\mathrm{VO} 2_{\max }$ (George et al, 1997), but, there are obvious limitations when using PFA data. For instance, individuals who are unfamiliar with prolonged aerobic exercise or unfamiliar with the pace it would take to cover 1 and 3 miles may report inaccurate PFA scores. Individuals who dislike jogging or running may underestimate their PFA score because they prefer to walk. Former athletes may overestimate their PFA score because they believe they still have the ability to run at a fast pace. About this issue Dustman-Allen et al. (2003) reported contrasting results in a cross validation of the N-EX regression equation developed by George et al. (1997). Dustman-Allen et al. (2003) assessed 66 participants who were similar in age (18-29 yr) to the validation group. The study reported $r$ and SEE values of 0.53 and $5.3 \mathrm{ml} \cdot \mathrm{kg}^{-1} \cdot \mathrm{min}^{-1}$ for females and 0.59 and 4.4 ml. $\mathrm{kg}^{-1} \cdot \mathrm{min}^{-1}$ for males. The measured and predicted $\mathrm{VO}_{\text {max }}$ values were similar for females, but dissimilar for males (10). It is difficult to explain why the results of the Dustman-Allen et al., (2003) study were so different than the present study and the original George et al. (1997) study. In addition, it is logical to assume that if Dustman-Allen et al., (2003) had not included the PFA data in the prediction of $\mathrm{VO} 2_{\text {max }}$ their results would have been worse. A possible reason why the PFA variable is effective is that it mimics the role of an EX variable and helps to classify participants as walkers, joggers, or runners based on their response to how fast they feel they can cover a one and three mile distance at a comfortable pace. Future studies need to clarify the accuracy of the PFA variable across various samples.

Additional predictor variables important in $\mathrm{VO} 2 \mathrm{max}$ estimation include age and body mass (or body composition). Various studies have shown age to be inversely related to $\mathrm{VO} 2 \mathrm{max}$ with typical age-related decrements in $\mathrm{VO} 2 \mathrm{max}$ averaging about $4 \mathrm{ml} \cdot \mathrm{kg}-1 \cdot \mathrm{min}-1$ per decade in adults as demonstrated by cross-sectional studies (George et al, 1997; Stamford, 1988). However, because this study involved a homogeneous sample of college students (aged 18-26 yr), age was not statistically significant in predicting $\mathrm{VO} 2 \max$ and consequently was dropped from the regression model. Various studies have also shown body mass, BMI, and/or body composition (\% fat) to be meaningful predictor variables in VO2max regression models (Ainsworth, 1992; Ebbeling et al, 1991; Jackson et al, 1980). Interestingly, the present sample of college students were relatively accurate (on average) in self reporting their body mass and height. We elected to use self-reported BMI as the predictor variable (Table 1) instead of self-reported body mass since self-reported BMI may be a more meaningful predictor variable in the educational and/or research setting. It is possible to measure body mass and height (and calculate BMI scores) and not have it self-reported, which may help to decrease some possible error. However, whether body mass and height are measured or self-reported probably has little bearing on the $\mathrm{VO}_{\text {max }}$ prediction as reported by Jackson et al. (1990) and George et al. (1997).

Finally, the present self-report N-EX regression model (Table.2) is unique in that $\mathrm{VO} 2_{\max }$ estimations can be computed entirely from questionnaire-based data. As such, this regression model may prove useful in large sample epidemiological studies when it is not feasible to measure the CRF of each subject and in large university wellness when traditional exercise tests are not practical to administer. Future work is now warranted to evaluate the specific utility and accuracy of self-report N-EX regression models in a variety of settings. The present N-EX regression models (Table.2) should provide valid estimations of $\mathrm{VO} 2_{\text {max }}$ for Azerbaijan -Iranian collegiate 
men student's who possess typical CRF scores. However, future cross validation of the present N-EX regression model is recommended prior to their use in older $(\geq 30$ yr) populations. In the event that the present N-EX regression equation is employed to estimate the $\mathrm{VO} 2_{\max }$ in older ( $\geq 30 \mathrm{yr}$ ) individuals, an appropriate age-correction factor should be used to account for the effect that age has on $\mathrm{VO} 2_{\max }$.

\section{Conclusion}

In conclusion, the new N-EX prediction model developed in this study provides an N-EX regression model that yields relatively accurate results and is a convenient way to predict VO2max in Azerbaijan -Iranian male collegiate students with a similar cardiorespiratory fitness level. The accuracy of this N-EX model is similar to many of the popular N-EX models. The results show that the modified PA-R variable significantly improves the ability of the regression model to accurately predict VO2max. Future studies are needed to evaluate the accuracy and generalizability of the PFA variable and NEX regression model in a variety of samples. Although the N-EX regression models developed in this study appear to provide a valid and convenient method for predicting VO2max in Azerbaijan-Iranian collegiate men student's, further cross validation of the equation is recommended prior to use in other samples.

\section{Acknowledgement}

Authors would like to acknowledge all the participants in this study.

\section{Reference}

Ainsworth, B. E., Richardson, M. T., Jacobs, D. R., \& Leon, A. S. (1992). Prediction of cardiorespiratory fitness using physical activity questionnaire data. Med. Exerc. Nutr. Health 1, 75-82.

American College of Sports Medicine. (2000). ACSM's Guidelines for Exercise Testing and Prescription (6th ed). Philadelphia PA: Lippincott Williams \& Wilkins.

Armstrong, N., Welsman, J.R., \& Kirby, B. J. (1988). Peak oxygen uptake and maturation in 12- $\mathrm{yr}$ olds. Med Sci Sports Exerc., 30, 165-169.
Bland, M .J., \& Altman, D. G. (1986). Statistical methods for assessing agreement between two methods of clinical measurement. The Lancet 1986, 1, 307-310.

Borg, G.A.V. (1982). Psychophysical bases of perceived exertion. Medicine and Science in Sports and Exercise, 14, 377-381.

Bradshaw, D. I., George, J. D., Hyde, A., LaMonte, M.J., Vehrs, P.R., Hager, R.L., \& Yanowitz F. G. (2005). An accurate VO2max nonexercise regression model for 18-65 year-old adults. Res $Q$ Exerc Sport.,76(4), 426-32.

Davis, J. A., Storer, T. W., Caiozzo, V. J., \& Pham, P. H. (2002). Lower reference limit for maximal oxygen uptake in men and women. Clin Physiol \& Func I m. 22, 332-338.

Dolgener, F. A., Hensley, L. D., Marsh, J. J., \& Fjestul, J. K. (1994). Validation of the Rockport Fitness Walking Test in college males and females. Res Q Exerc Sport., 65, 152-158.

Donnelly, J. E., Jacobsen, D. J., Jakicic, J. M., Whatley, J., Gunderson, S., Gillespie, W. J., Blackburn, G. L., \& Tran, Z. V. (1992). Estimation peak of oxygen consumption from a sub-maximal half mile walk in obese females. Int J Obes Relat Metab Disord. 16, 585-589.

Dustman-Allen, K. M., \& Plowman, S. A. (2003). Validation of a non-exercise regression equation for the prediction of maximal aerobic capacity. Medicine and Science in Sports and Exercise, 35, S310.

Ebbeling, C. B., Ward, A., Puleo, E. M., Widrick, J., \& Rippe, J. M. (1991). Development of a single-stage submaximal treadmill walking test. Med. Sci. Sports Exerc., 23, 966-973.

George, J. D., Vehrs, P., Allsen, P. E., Fellingham, G. W., \& Fisher, A. G. (1993). VO2max estimation from a submaximal 1-mile track jog for fit college-age individuals. Med Sci Sport Exerc., 25, 401-406.

George, J. D., Stone, W. J., \& Burkett, L. N., (1997). Non-exercise VO2max estimation for physically active college students. Medicine and Science in Sports and Exercise, 29(3), 415-423. 
Godin, G., \& Shephard, R. J. (1985). A simple method to assess exercise behavior in the community. Can. J. Appl. Sport Sci., 10, 141-146.

Grant, J. A. , Joseph, A. N., \& Campagna, P. D. (1999). The prediction of Vo O2max: a comparison of 7 indirect tests of aerobic power. J Strength Cond Res., 13, 346-352.

Greenhalgh, H. A., George, J. D., \& Hager, R. L. (2001). Cross-validation of a quarter-mile walk test using two VO2max models. Meas Phys Ed Exerc Sci., 5, 139-151.

Heil, D. P., Freedson, P. S., Ahlquist, L. E., Price, J. , \& Rippe, J. M. (1995). Nonexercise regression models to estimate peak oxygen consumption. Med. Sci. Sports Exerc., 27, 599-606.

Howley, E. T., Bassett Jr, D. R., \& Welch, H.G. (1995). Criteria for maximal oxygen uptake: review and commentary. Med Sci Sports Exerc., 27, 1292-1301.

Jackson, A. S., Pollock, M. L., \& Ward, A. (1980). Generalized equations for predicting body density of women. Med. Sci. Sports Exerc., 12, 175-182.

Jackson, A. S., Blair, S. N., Mahar, M. T., Weir, L. T., Ross, R. M., \& Stuteville, J. E. (1990). Prediction of functional aerobic capacity without exercise testing. Med. Sci. Sports Exerc., 22, 863-870.

Kolkhorst, F. W., \& Dolgener, F. A. (1994). Nonexercise model fails to predict aerobic capacity in college students with high VO2peak. Res. Q. Exerc. Sport, 65, 78-83

Larsen, G. E., George, J. D., Alexander, J. L., Fellingham, G. W., Aldana, S. G., \& Parcell, A. C. (2002). Prediction of maximum oxygen consumption from walking, jogging, or running. Res $Q$ Exerc Sport., 73, 66-72.

Matthews, C. E., Heil, P. D., Freedson, P. S., \& Pastides, H. (1999). Classification of cardiorespiratory fitness without exercise testing. Med Sci Sports Exerc., 31, 486-493.
Oja, P, Laukkanen, R., Pasanen, M., Tyry, T, \& Vuori, I. (1991). A 2-km walking test for assessing the cardiorespiratory fitness of healthy adults. Int $J$ Sports Med., 12, 356-362.

Siconolfi, S. F., Lasater, T. M., Snow, R. C., \& Carleton, R. A. (1985). Self-reported physical activity compared with maximal oxygen uptake. Am. J. Epidemiol., 122, 101-105.

Stamford, B. A. (1988). Exercise and the elderly. Exerc. Sport Sci. Rev., 16, 341-379.

Vehrs, P., George, J. D., \& Fellingham, G. W. (1998). Prediction of VO2max before, during, and after 16 weeks of endurance training. Res $Q$ Exerc Sport., 69, 297-303.

Wasserman, K., Hansen, J., Sue, D,Y., Casaburi, R., \& Whipp, B.J.(1999). Principals of exercise testing and interpretation (3rd ed). Philadelphia: Lippincott, Williams \& wilkins.

\section{Correspondence}

Dr. Abbas Meamarbashi

Department of Physical Education

and Sports Sciences,

University of Mohaghegh Ardabili,

56199-11367 Ardabil, Iran

Tel./Fax: +98 4515516815

E-mail address: a_meamarbashi@yahoo.com 